\title{
THE GRAPHIC EVALUATION OF A BREEDING SYSTEM
}

\author{
GORDON HASKELL \\ John Innes Horticultural Institution, Hertford
}

Received 30.xii.52

\section{INTRODUCTION}

MAIze varieties in the field vary in their self-pollination. This indicates that control of the inbreeding-outbreeding mechanism is not so simple as is usually supposed. Usually a population's mean outcrossing or selfing has been recorded, with neglect of plant to plant variation. Behaviour of individual plants within a population has not been considered. The variation has been reduced to a mean which conceals or rejects some of the most useful information.

Maize is a monoecious (with male and female flowers separate on the same plant) outcrossing species with the possibility of inbreeding. The table gives the average inbreeding for different populations under different environments. These values, however, depend on similarities between the tested and tester variety for characters, such as relative flowering times, affecting dissemination and reception of pollen.

Jones and Brooks (1950) have listed nine factors affecting natural outcrossing in cross-pollinated grasses. They have omitted protandry and protogyny, and also plant to plant variation in flowering time, presumably assuming these to be of little interest. Yet these properties must be of cardinal importance for the breeding system of maize. Even extensive contamination studies have failed to determine the amount of inbreeding and outbreeding between and within plants of one variety.

Recently I have made a multiple regression analysis on silking time (protrusion of styles), tasselling time (opening of anthers with consequent shedding of pollen) and dichogamy, or the difference of the two in time, in order to determine their influences on out-crossing of sweet corn inter-planted with a flint variety. All effected contamination (Haskell, I953). However, besides knowing behaviour of varieties as a whole, knowledge of individual behaviour within each is also valuable, as dichogamy relations of the breeding system are important in the evolution of species (cf. Darwin, 1888). A graphic method, suggested by Dr Darlington, is given here of rapidly evaluating individual behaviour within a population.

Dichogamy consists of protandry and protogyny, each of which may be partial or absolute: absolute protandry is when stamens are ripe and all pollen has been shed before the stigmas are receptive, so that no self-pollination occurs within the flower; partial protandry 
is when much of the pollen is shed prior to the styles ripening, but there is some overlapping so that some of the earliest styles may receive pollen shed by late anthers. Protogyny is equivalent to negative protandry: with absolute protogyny the styles and stigmas are receptive and are already fertilised, or inactivated, before pollen starts to shed ; or some of the styles are still receptive when the pollen is being liberated (partial protogyny).

There is a further complication in maize that the ears, really female inflorescences, do not open at the same time : the main ear usually opens ahead of the secondaries. In the fint types of both maize and sweet corn, with which we are here dealing, one ear alone predominates. In dent types there are several ears opening consecutively, so that the amount of inbreeding or outbreeding is further complicated, being dependant on the position of the female inflorescence on the plant.

\section{EXPERIMENTAL DATA}

Professor K. Mather's data were used. These recorded first pollen shedding, and date silks first appeared on main ears of plants in two maize varieties, a flint and sweet corn, sown 24th May 1945. Fifty plants of each were raised at random in two adjacent plots. Data from both were pooled. There were altogether 94 flints and 87 sweets, as a few plants died.

TABLE

Self-fertilisation in maize populations

\begin{tabular}{|c|c|c|}
\hline Comment & Selfing & Author \\
\hline $\begin{array}{l}\text { Dent corn in Nebraska. Both } \\
\text { varieties with the same flowering } \\
\text { periods }\end{array}$ & 0.70 per cent. & Kiesselbach, I 922 \\
\hline $\begin{array}{l}\text { Dent corn in Maryland. Average } \\
\text { of five years }\end{array}$ & $\left\{\begin{array}{l}3 \cdot 70 \\
5.00\end{array}\right.$ & $\begin{array}{l}\text { Kemp and Rothgeb, } 1943 \\
\text { Hayes, } 1918\end{array}$ \\
\hline $\begin{array}{l}\text { Maize crops generally throughout } \\
\text { U.S.A. }\end{array}$ & $\left\{\begin{array}{l}5 \cdot 00 \\
5 \cdot 13\end{array}\right.$ & $\begin{array}{l}\text { Wallace and Bressman, } 1949 \\
\text { Waller, } 1917\end{array}$ \\
\hline
\end{tabular}

Figures represent means of isolated plants surrounded by plants of another variety. Outcrossing was detected with marker genes, e.g. $\Upsilon_{-y}$.

\section{THE TWO-DIMENSIONAL GRAPH}

Fig. I gives a conventional plant breeding method of estimating earliness and uniformity. The percentage of flints and sweets commencing to flower during July are given, with silking and tasselling plotted separately. The graph indicates broadly that flints silked considerably earlier than they tasselled; the crop burst into pollen shedding. A few later flowering stragglers are depicted along the 
bottom right of the graph. The sweet variety gradually came into flower, and was somewhat later than the flint. Several late silkers are also shown.

This method has several disadvantages. Sunday measurements are absent, so introducing irregularities. More important, silking and tasselling relations of individuals within a variety are not shown.

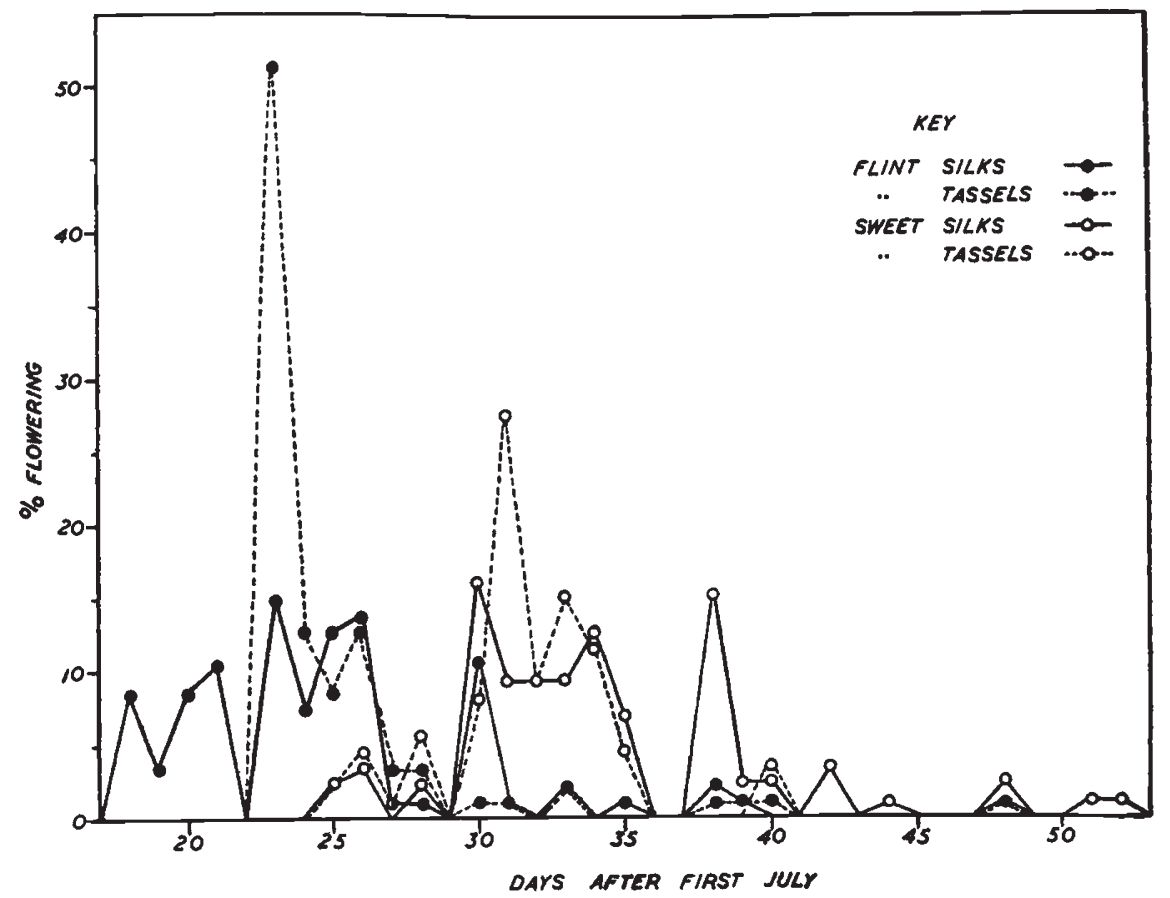

Fig. 1.-Conventional two-dimensional method of plotting earliness and uniformity. Open circles refer to sweet corn plants; black circles refer to flinty maize.

\section{THE THREE-DIMENSIONAL GRAPH}

The same data are plotted in fig. 2. An arithmetical scale replaces actual flowering date in July. Silking date is plotted along the $\mathrm{Y}$-axis, and tasselling date along the $\mathrm{X}$-axis. Individual behaviour can now be charted ; as several plants were alike, circles of relative sizes are used to indicate how many have the same flowering relations. Percentages need not be calculated. Full and open circles respectively indicate flint and sweet corns. Circles on the dotted line represent plants silking and tasselling on the same day. Circles below the line are protogynous plants, while those above are protandrous; distance from the line is proportional to the amount of protandry or protogyny.

The breeding behaviour in both populations is now readily evaluated. The earliest flints are highly protogynous and represent a large proportion of the population. Slightly later ones are more homogamous. Latest ones tend to be more and more protandrous ; 
however, some of the last flints to flower are also highly protogynous. The earliest sweet corn plants show little dichogamy but within the population there is a definite trend: later plants have a greater tendency to be protandrous. Only a few plants in the middle flowering period of the populations are protogynous. The best fitting straight line for the sweet corn data was calculated. This was $Y=I \cdot I 6 X-2 \cdot 7 I$, and is plotted in fig. 2.

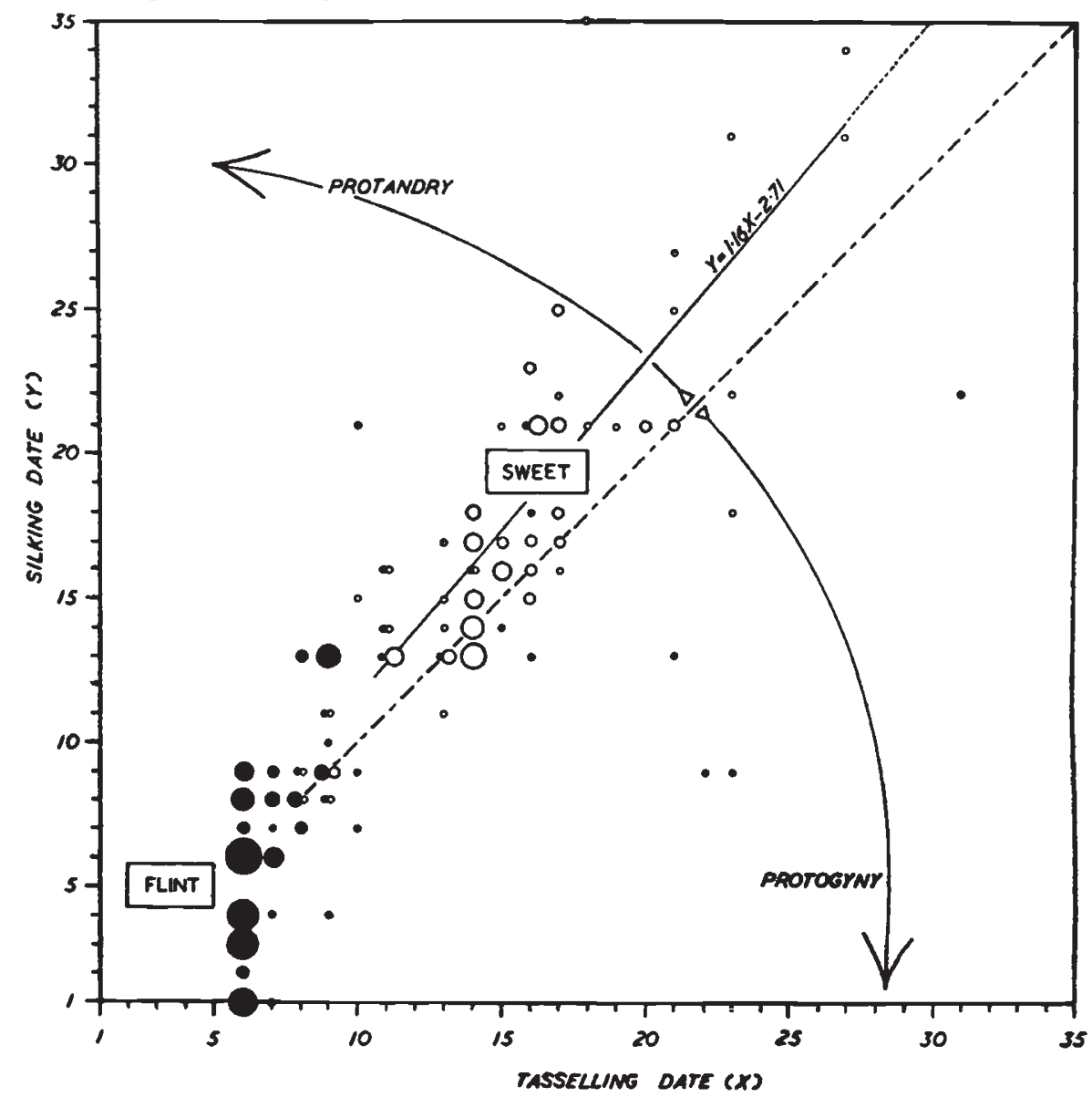

Frc. 2.-Three-dimensional method of plotting earliness and uniformity. Open circles refer to sweet corn plants; black circles refer to flinty maize. Size of circles is proportional to number of plants. $Y=1 \cdot 16 \mathrm{X}-2 \cdot 7 \mathrm{I}$ is the best fitting straight line for sweet corn values.

\section{FLOWERING TIME AND THE BREEDING SYSTEM}

Fig. I describes population behaviour without considering the individuals within it. It assumes that these are generally the same, except for their time of flowering. The breeding system of two populations in the same environment is also described in fig. 2, using a three-dimensional graph. This provides information not previously apparent. 
The amount of selfing in a plant depends on availability of its own pollen. Hence earliest sweet corn plants have less chance of selfing, as they have available a pollen mixture before and after tasselling commences. Outbreeding is also more likely to be higher when plants are protogynous : this is mostly among earliest plants in both populations. Seeds from the earlier portion of the population, therefore, possibly include more heterozygotes than those from later plants. More vigorous offspring would thus come from earlier plants, because vigour in maize partly depends on heterozygosity. The stragglers are not only later, but pollen choice is limited. Being more protandrous, their own pollen is shedding when their silks emerge. Latest plants therefore have greater chances of selfing, especially as silks do not emerge simultaneously but often spread over several days. More of their seeds would then be inbred. Now inbred maize is generally later than the original open pollinated parent, hence the next generation from these seeds would be still later. Again they are more likely to be protandrous and to inbreed both within and between themselves. Thus, genetically, a vicious circle is set up, so that besides being temporally isolated from the bulk of most of the crop's pollen, homozygosity is even further forced on them.

Duration of pollen shedding, which has not yet been recorded in England, influences the inbreeding-outbreeding mechanism, so that absolute protandry does not actually occur in maize. Even though absolute protandry discourages self-pollination, it is still not fool-proof (Mather, 1940). The floral mechanism of maize has, however, arisen by artificial selection and is a particular condition : here, protandry has not been so important as sex separation within the plant. Duration of pollen shedding in the U.S.A. varies from two to fourteen days according to variety and most silks under favourable conditions are pollinated on day of emergence with ears completely pollinated within three days (Kiesselbach, 1949). Hence all degrees of inbreeding and outbreeding are possible.

The genetical aspects of dichogamy in maize were earlier investigated by Kempton (1924). He found that although maize is protandrous with occasional exceptions, when a protogynous Spanish popcorn was crossed with a protandrous maize, the $\mathrm{F}_{\mathrm{I}}$ were protandrous. The $\mathrm{F}_{2}$ segregated to give a greater mean protandry and a few protogynous plants. Kempton believed protogyny was a reversion to an ancestral condition, being normal for Tripsacum and Euchlaena; it was probably not due to photoperiodism, but might have been a manifestation of male sterility which may postpone anther opening. No male sterility occurred in the flint variety used in the present experiment, so that male sterility is not a controlling factor here. Other cereals are also known in which the dichogamy relations vary according to the genotype: in rye, Vavilov (195I) found both cross- and self-pollinated forms, with it normally being regarded as outcrossing in Asia. 


\section{METHODS OF REPRESENTATION}

Some consideration may now be given to other methods used by maize breeders for illustrating the flowering of maize. Shaw and Thom (195I) have plotted silking time-rate (days from $5^{\circ}$ per cent. silking), positive or negative, against percentage of plants silked. In this way they compared a variety's rate of silking over several years. This method could be extended for studying environmental and other effects on flowering. Compared with fig. 2, it involves additional calculation of differences from the mean, and percentages. Yet it quickly demonstrated that for hot, dry years in the mid-West tassels rapidly appeared and had earlier pollen shedding, while there was a slower silking rate. Tassels appeared more slowly yet with more rapid silking in cooler, moister years. Thus, in the present data, climate might have influenced the earliest flint plants, which suddenly burst into pollen shedding. This is unlikely, however, since pollen shedding and silking for varieties sown at monthly intervals in England show high correlation regardless of climatic differences (Haskell, 1949a). That climate does influence the inbreeding-outbreeding system of some species is seen in wheat which is $99 \cdot 9$ per cent. self-pollinated in England, but shows increased outcrossing in drier climates (Vavilov, I95I).

When studying the effects of sowing date on the rate of sweet corn tasselling ( $1949 b)$ I suggested a graph in which probit transformation of tasselling time is plotted against the logarithm of the flowering date. This helps to straighten the sigmoid-like curves so that uniformity and rate of tasselling can more readily be assessed. Cornfield (1949) objected to this on the grounds that probits could be used only for discrete values. The effect of the probit transformation, however, is to straighten sigmoid curves when ordinates are measured on a linear scale of probits instead of percentages ( $c f$. Finney, 1947). Hence their use is legitimate here.

Another graphical way of displaying flowering time data is that of Singleton (1948) who graphed the percentage of silks which had emerged and of plants shedding pollen against date for four sowings of many sweet corn inbreds in Connecticut. Scaling was such that I oo per cent. silking equalled 50 per cent. shedding pollen; hence critical sowing date for producing hybrid seed is rapidly determined. This allows a rapid visual test of whether two inbreds will flower together, important when planning cross-pollination for hybrid seed production. Singleton's graphs show that pollen shedding normally starts before silks appear. The roo per cent. tasselling is always reached ahead of Ioo per cent. silking, and pollen shedding always continues for several days after silking is completed. The present graph should similarly be useful for comparing the breeding behaviour not only of ordinary maize varieties, inbreds and single-cross and double-cross populations, but of other plant species. 


\section{SUMMARY}

I. Individual silking date, time of first pollen shedding and number of plants of maize together plotted in a three dimensional graph give more information on the breeding system than the conventional plotting of percentage flowering against time.

2. The breeding behaviour of individuals within a population and between two inter-breeding populations is also readily assessed. Protandry in maize is not so important for out-breeding as being monoecious.

3. The relation of dichogamy with flowering time is also seen. Earliest plants in both populations were more protogynous and hence more outbred than later plants, which were more protandrous. These shed their pollen while silks are emerging and therefore have greater chance of inbreeding. The genetical consequences of this breeding system is evaluated in relation to heterosis.

4. The three-dimensional graph is compared with other graphic methods of representing flowering in maize. It is useful for comparing the uniformity and breeding systems of ordinary maize, inbreds and single-cross and double-cross populations.

\section{REFERENCES}

CORNFIELD, J. 1950. The probit method. Science, III, 43.

DARwin, G. I888. Cross and Self-fertilisation of Plants, 2nd Ed. London : J. Murray. FInNey, D. J. 1947. Probit Analysis. Cambridge : University Press.

haskell, G. I949a. Studies with sweet corn. II. Sowing dates and plant characters. Emp. 7. Exp. Agr., I8, I-7.

haskell, G. 1949b. Application of probits to sweet corn earliness data. Science, IO9, 544.

HASKELl, G. 1953. The control of inter-pollination between sweet and flint corn. Ann. Bot., N.S. 17,8 I-93.

hayes, H. к. 1918. Normal self-fertilisation in corn. J. Amtr. Soc. Agron., Io, I $23-126$.

JONES, M. D., AND BROOKs, J. S. 1950. Effectiveness of distance and border rows in preventing outcrossing in corn. Tech. Bull., T. 38, Oklahoma A.E.S.

KEMP, w. B., AND ROTHGEB, R. G. 1943. Selection and genetic responses in a segregating maize population. Bull. A. 26, Maryland A.E.S.

кEMPTON, 1. H. 1924. Inheritance of proterogyny in maize. Amer. Nat., $5^{8}$, $182-187$.

kiesselbach, T. A. 1922. Corn investigations. Res. Bull., 20, Nebraska A.E.S.

MATHER, K. 1940. Outbreeding and separation of the sexes. Nature, 145, 484-486. SHAW, R. H., AND THOM, H. c. S. I95I. On the phenology of field corn, the vegetative period. Agron. $7 ., 43,9-15$.

singleton, w. R. 1948. Hybrid sweet corn. Bull. $5^{18}$, Conn. A.E.S.

VAvilov, N. I. I951. The Origin, Variation, Immunity and Breeding of Cultivated Plants. Mass. : Waltham.

WALler, A. E. I9I7. A method for determining the percentage of self-pollination in maize. 7. Amer. Soc. Agron., 9, 35-37.

wallace, H., and bressman, E. N. 1949. Corn and Corn Growing. New York and London : John Wiley \& Sons Inc. 